\title{
Sagittal Unicondylar Fracture of the Femur on Nail of Küntscher
}

\author{
Tchatchuang Paul Urich Tambekou1, Batarabadja Bakriga', Noufanangue Kombate ${ }^{2}$, \\ Atchi Walla1, Anani, Abalo1, Assang Michel Dossim¹ \\ ${ }^{1}$ Department of Orthopaedics Tokoin Teaching Hospital, Lomé, Togo \\ ${ }^{2}$ Afagna Hospital, Afagnan, Togo \\ Email: mbakriga@gmail.com
}

How to cite this paper: Tambekou, T.P.U., Bakriga, B., Kombate, N., Walla, A., Abalo, A. and Dossim, A.M. (2017) Sagittal Unicondylar Fracture of the Femur on Nail of Küntscher. Open Journal of Orthopedics, 7 , 192-197.

https://doi.org/10.4236/ojo.2017.77021

Received: June 8, 2017

Accepted: July 22, 2017

Published: July 25, 2017

Copyright $\odot 2017$ by authors and Scientific Research Publishing Inc. This work is licensed under the Creative Commons Attribution International License (CC BY 4.0).

http://creativecommons.org/licenses/by/4.0/

\begin{abstract}
Unicondylar fractures of the femur on osteosynthesis equipment are a particular entity in terms of the lesion mechanisms and therapeutic difficulties. We report this case because of its exceptional nature and discuss the mechanism of occurrence. It was a lateral sagittal unicondylar fracture of the femur on a nail of Küntscher that had been laid for medio-diaphyseal fracture. The causal mechanism was direct. A double screwing on each side of the nail after an open reduction followed by an early rehabilitation was carried out. Consolidation was obtained at 3 months and the nail removed at 18 months with a good functional knee result. Anatomical reduction and fixation allowing early rehabilitation represent a guarantee for a good long-term result.
\end{abstract}

\section{Keywords}

Fracture, Unicondylar, Femur, Nail of Küntscher, Surgical Treatment

\section{Introduction}

Unicondylial fractures of the femur are lesions commonly observed in association with other lesions of the knee region. Unicondylar fractures are frequently displaced and unstable because of the initial trauma force, the muscle contraction, in particular, the gastrocnemius and popliteus muscles which can rotate and move the condylar fragments [1]. The causal mechanism is usually indirect; the knee flexes anatomical reduction followed by osteosynthesis is essential for a better result and a good functional prognosis of the knee in the long term [2]. We report a rare case of lateral unicondylar fracture with sagittal femur stroke on nail of Küntscher.

\section{Case Presentation}

The cas included a 38-year-old patient, teacher, with a history of closed fracture 
with a medio-diaphyseal cross-section of the left femur a year ago treated by a nail of Küntscher. He came for consultation due to pain and relative functional impotence of the left pelvic limb evolving for 24 hours secondary to a closed trauma of the knee by direct impact in the aftermath of a motorcycle-motorcycle accident. On examination there was a painful swelling of the left knee without a skin opening with a positive patellar shock, the vascular and nervous examination of the left pelvic limb were normal as well as the rest of the examination. Frontal and profile knee x-rays were performed and showed a displaced sagittal fracture of the lateral condyle on nail of Küntscher (Figure 1). In order to better analyze lesions and plan the surgical strategy, a left knee computed tomography (CT) was performed and the diagnosis was confirmed (Figure 2 and Figure 3 ). Axial and frontal CT cross section showed displaced sagittal fracture of the lateral condyle. Three days after the accident, under spinal anesthesia, the patient underwent surgery by the lateral approach; a reduction of the fracture was made followed by a double screwing on both sides of the nail (Figure 4). Vertical rise

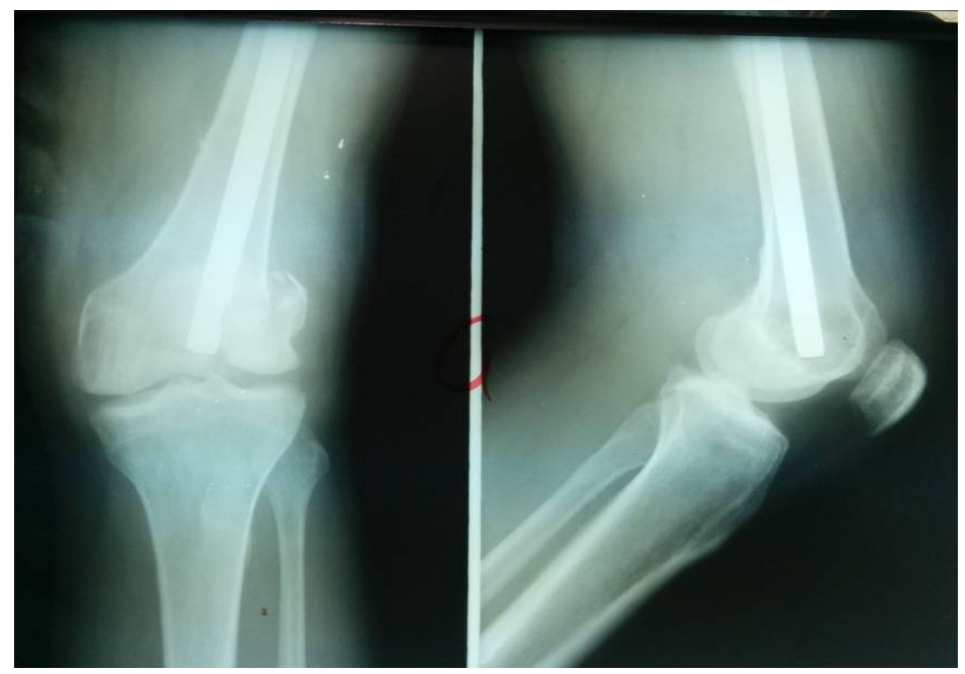

Figure 1. X-ray of the left knee F/P.

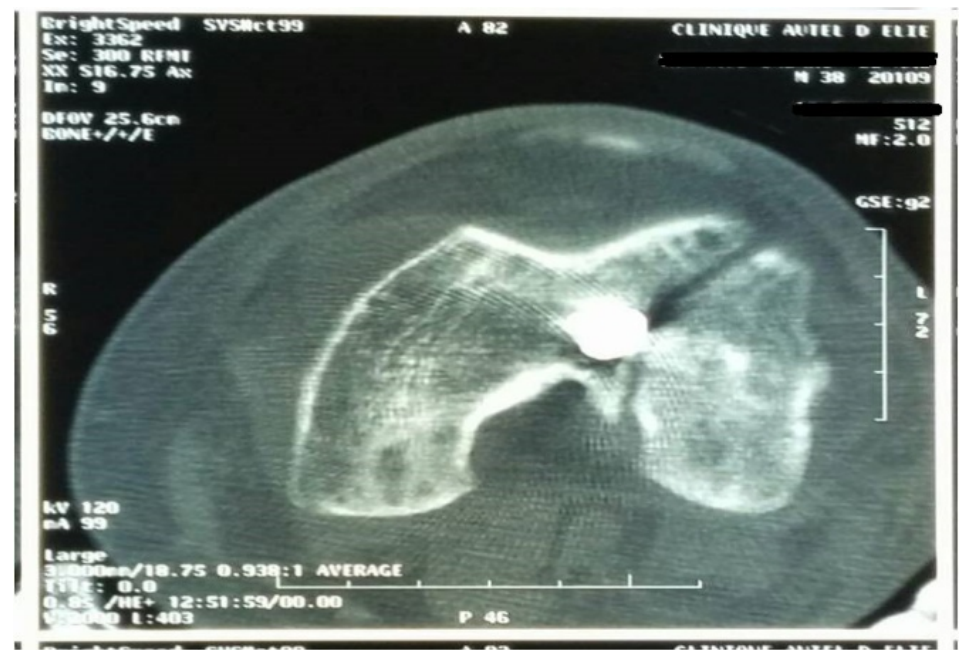

Figure 2. Axial CT cross section of condyles. 


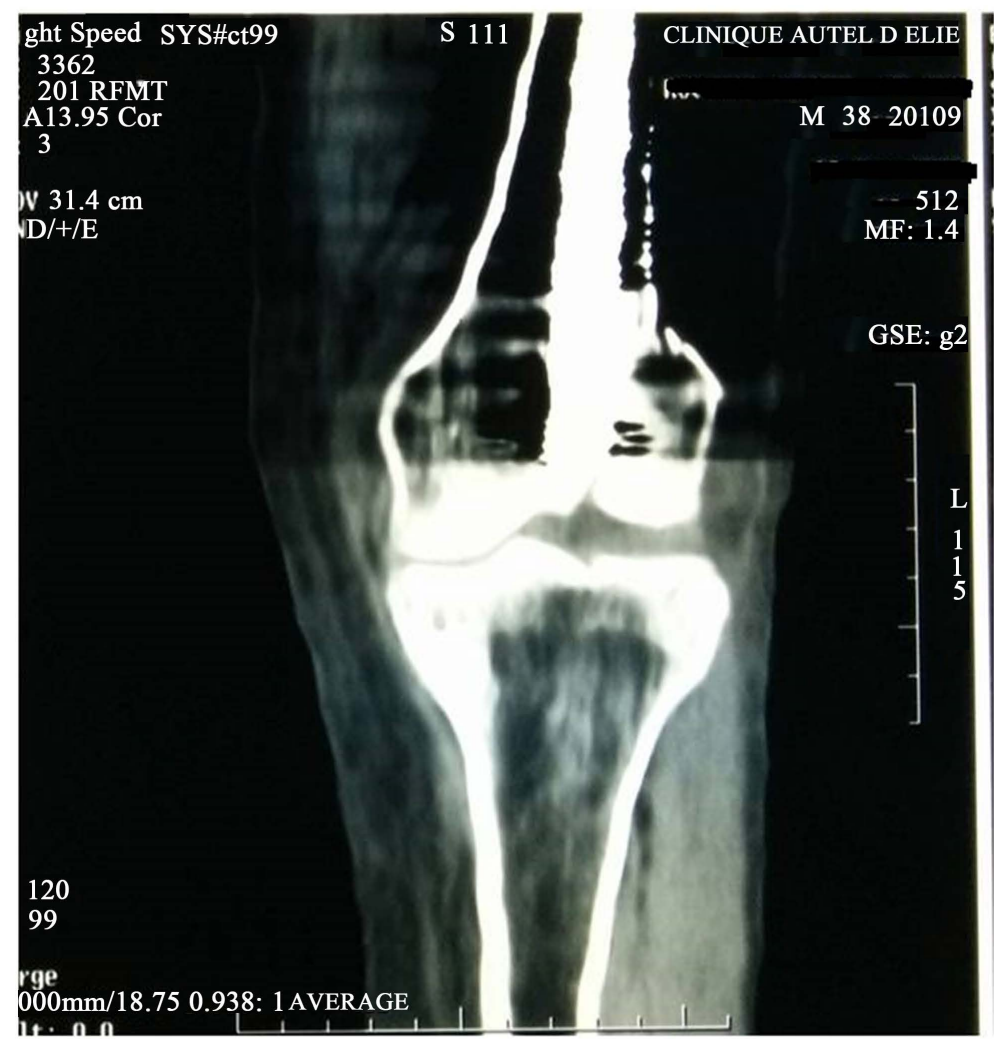

Figure 3. Frontal CT cross section of the knee.

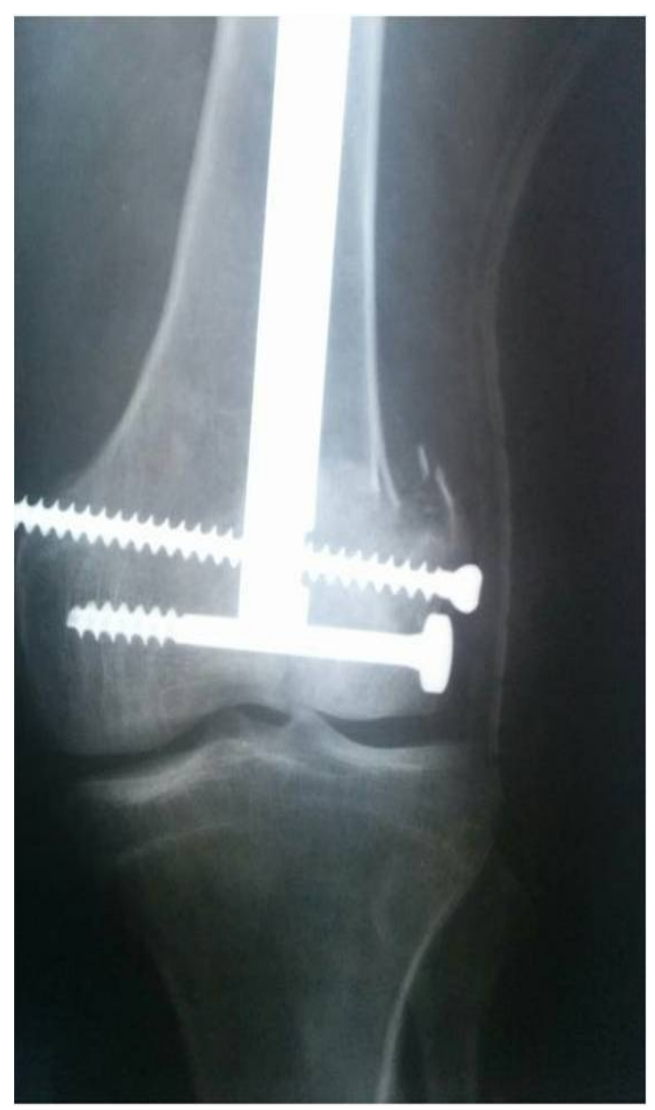

Figure 4. X-ray control of the knee in front. 
without support was permitted the next day as well as knee rehabilitation. A 3month postoperative consolidation was confirmed by the X-ray of the knee at the follow-up appointment (Figure 5), and total loading was authorized. At 18 months postoperative the patient had no knee pain at rest and walking, had a good knee flexion of $135^{\circ}$ and complete extension (Figure 6 and Figure 7), and removal of the nail was performed at 18 months.

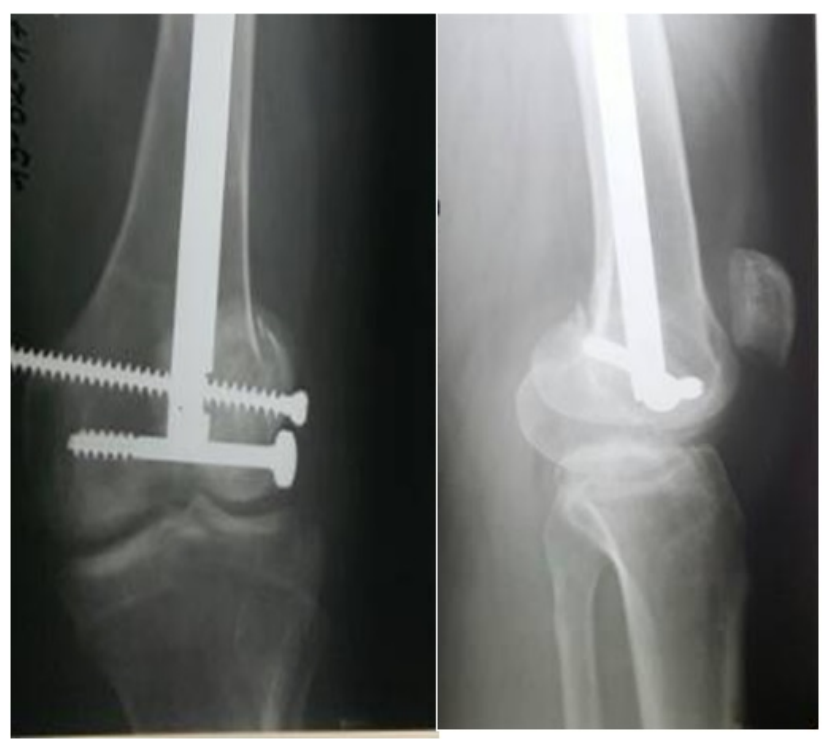

Figure 5. X-ray control of the knee at 3 months in front and profil.

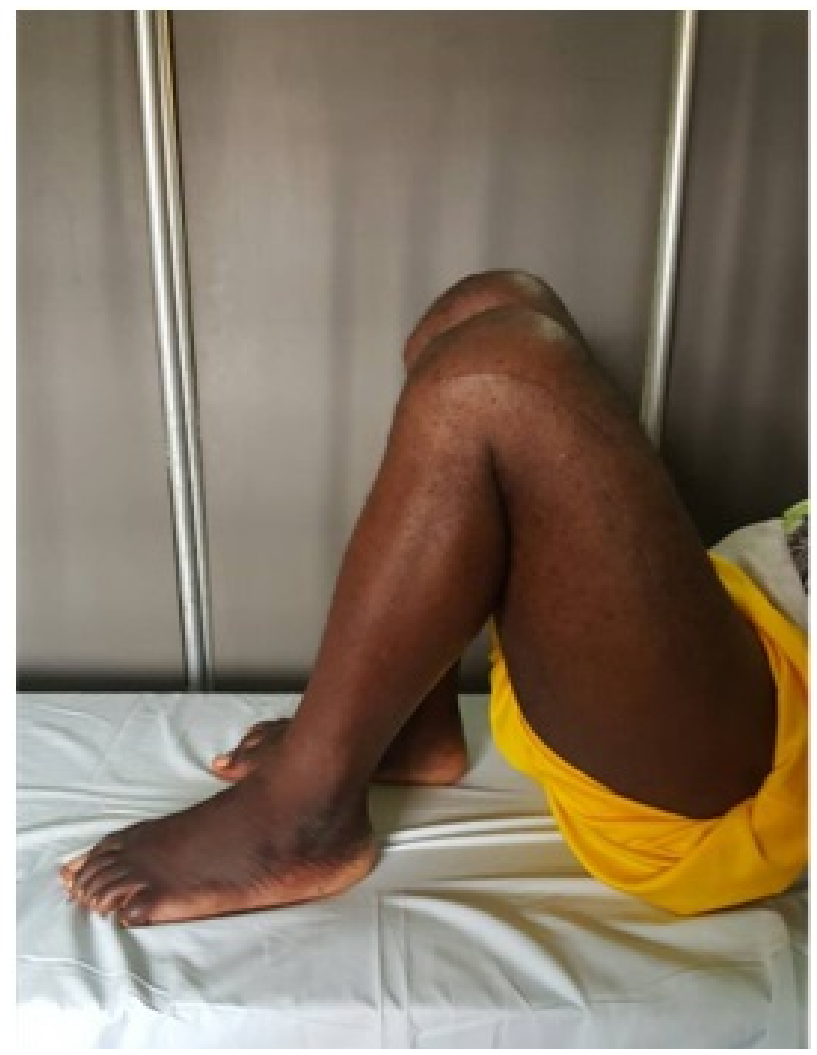

Figure 6. Flexion of knee at 18 months. 


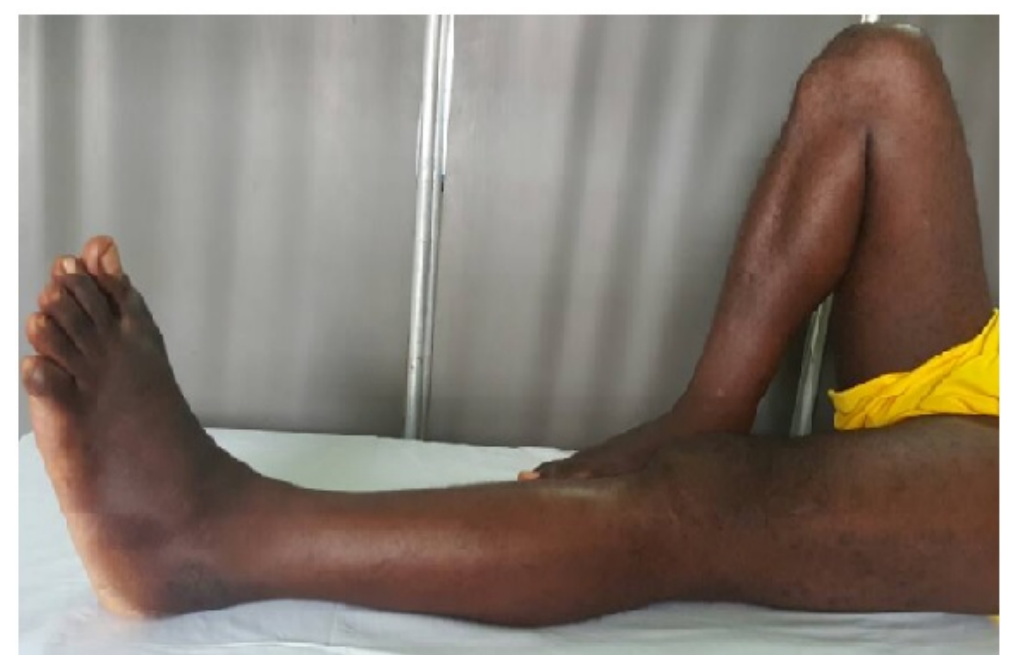

Figure 7. Extension of knee at 18 months.

\section{Discussion}

Unicondylial fractures of the femur often cause a diagnostic challenge because they go unnoticed or, they are occasionally associated with complex fractures of the same region. They most often occur by an indirect mechanism by dashboard syndrome in the course of the road accidents as in our context, or sport accidents [3]. The lateral condyle of the trochlea is wider and is more exposed to the trauma than the medial condyle [4]. In the case of our patient, the unicondylial fracture was classified type B1 according to the AO classification [5]. To our knowledge, a sagittal unicondylar fracture with on nail of Küntscher has not yet been reported in the literature hence the interest of this study. The causal mechanism in our case was direct and we believe that the excessive depth of a nail of Küntscher in the trochlea would have increased the fragility of the lateral condyle. For a medio-diaphyseal fracture of the femur treated with a nail of Küntscher, the distal nail must be at the level of the patella. The physical examination reveals in general a painful swelling of the knee in traumatic context, a relative functional impotence of the pelvic limb, and clinical signs of intra-articular effusion as in the case study. Face and profile knee $\mathrm{x}$-rays are first-line incidences and can be supplemented by a knee CT to confirm the diagnosis, to better appreciate the lesions and to propose a better therapeutic decision [6]. Today, surgical treatment is most recommended and consists of an open-air reduction followed by stabilization by different materials such as a condylar spongy screw, a cannulated screw, a condylar plate or a screw-plate [4]. In our case, in order to obtain anatomical reduction, good internal stability and early knee rehabilitation, we performed an osteosynthesis with two spongy screws of diameter $6.5 \mathrm{~mm}$ after a reduction of the fracture. We did not remove the nail of Küntscher during the screwing because the bone callus in medio-diaphyseal was not mature and the delay required for ablation is 18 months. We obtained a good functional result of the knee in the long term according to the International Knee Score (Figure 6 and Figure 7), this result support the conclusion of Bel 
JC and collaborators who think that the anatomical reduction and a stable internal fixation with immediate rehabilitation assure a good result [7].

\section{Conclusion}

The sagittal unicondylar fracture of the femur on a nail of Küntscher is a rare lesion; unicondylar fractures in a young patient generally occur following a trauma of high energy. In this case, we believe that the presence of the nail of Küntscher would have increased the fragility of the lateral condyle. Anatomical reduction and fixation allowing early rehabilitation represent a guarantee for a good long-term result.

\section{References}

[1] Helfet, D.L. (1994) Fratture monocondiloidee di femore. In: Browner, B.D. et al., Eds., Traumatologia dell'apparatoMuscolo-Scheletrico, Verduci Editore, Roma, 4, 1721-1765.

[2] Gwathmey, F.W., Jones-Quaidoo, S.M., Kahler, D., Hurwitz, S. and Cui, Q. (2010) Distal Femoral Fractures: Current Concepts. The Journal of the American Academy of Orthopaedic Surgeons, 18, 597-607. https://doi.org/10.5435/00124635-201010000-00003

[3] Strauss, E., Nelson, J.M. and Abdelwahab, I.F. (1984) Fracture of the Lateral Femoral Condyle: A Case Report. Bulletin of the Hospital for Joint Diseases, 44, 86-90.

[4] Trillat, A., Dejour, H., Bost, J. and Nourissat, C. (1975) Unicondylar Fractures of the Femur. Revue de chirurgie orthopedique et reparatrice de 1 appareil moteur, 61, 611-626.

[5] Müller, M.E., Nazarian, S. and Koch, P. (1987) Classification AO des Fractures. Springer-Verlag, New York. https://doi.org/10.1007/978-3-662-06263-0

[6] Ostermann, P.A., Neumann, K., Ekkernkamp, A. and Muhr, G. (1994) Long Term Results of Unicondylar Fractures of the Femur. Journal of Orthopaedic Trauma, 8, 142-146.https://doi.org/10.1097/00005131-199404000-00011

[7] Bel, J.C., Court, C., Cogan, A., Chantelot, C., Piétu, G. and Vandenbussche, E. (2014) Unicondylar Fractures of the Distal Femur. Orthopaedics \& Traumatology: Surgery \& Research, 100, 873-877. https://doi.org/10.1016/j.otsr.2014.10.005 
Submit or recommend next manuscript to SCIRP and we will provide best service for you:

Accepting pre-submission inquiries through Email, Facebook, LinkedIn, Twitter, etc. A wide selection of journals (inclusive of 9 subjects, more than 200 journals)

Providing 24-hour high-quality service

User-friendly online submission system

Fair and swift peer-review system

Efficient typesetting and proofreading procedure

Display of the result of downloads and visits, as well as the number of cited articles Maximum dissemination of your research work

Submit your manuscript at: http://papersubmission.scirp.org/

Or contact ojo@scirp.org 